\title{
Examination of renal function in infants with a history of intrauterine growth restriction up to 36 weeks gestation compared to infants with normal growth
}

\author{
*Makmur Sitepu ${ }^{1}$ \\ Sri Lanka Journal of Child Health, 2017; 46(2): 152-154
}

\begin{abstract}
Background: Intrauterine growth restriction (IUGR) will increase the risk of impairment of renal function in the future.
\end{abstract}

Objective: To assess renal function in infants with a history of IUGR up to 36 weeks gestation compared to infants with normal growth.

Method: Laboratory examination of urine microalbumin, urine creatinine and a cystatin $\mathrm{C}$ blood test were done on day 7 after birth in infants with a history of IUGR and in infants with normal growth up to 36 weeks gestation and compared.

Results: On day 7 after birth, mean urine microalbumin levels of IUGR and normal weight infants were $15.83 \pm 31.32 \mathrm{mg} / \mathrm{ml}$ and $1.9 \pm 0.97$ $\mathrm{mg} / \mathrm{ml}$ respectively $(\mathrm{p}<0.01)$. Mean urine creatinine levels of IUGR and normal weight infants were $17.19 \pm 9.84 \mathrm{mg} / \mathrm{L}$ and $8.22 \pm 2.85 \mathrm{mg} / \mathrm{L}$ respectively $(\mathrm{p}<0.01)$. Mean albumin/creatinine ratios of IUGR and normal weight infants were 198 $\pm 627.63 \mu \mathrm{g} / \mathrm{mg}$ and $24.75 \pm 14.07 \mu \mathrm{g} / \mathrm{ml}(\mathrm{p}<0.01)$. Mean cystatin C levels of IUGR and normal weight infants were $1.47 \pm 0.28 \mathrm{mg} / \mathrm{ml}$ and $1.45 \pm$ $0.19 \mathrm{mg} / \mathrm{ml}$ respectively $(\mathrm{p}>0.05)$.

Conclusions: Mean urine albumin level, mean urine creatinine level and mean urine albumin/creatinine ratio of IUGR infants were significantly higher than those of normal weight infants. There was no significant difference between the mean cystatin $\mathrm{C}$ levels of IUGR infants and normal weight infants.

DOI: http://dx.doi.org/10.4038/sljch.v46i2.8272

${ }^{1}$ Head of Maternal Fetal Medicine, H. Adam Malik Hospital, Medan, Indonesia

*Correspondence: makmurstp@gmail.com (Received on 31 July 2016: Accepted after revision on 23 September 2016)

The authors declare that there are no conflicts of interest

Personal funding was used for the project.

Open Access Article published under the Creative

Commons Attribution CC-BY CC License
(Keywords: Renal function of infants with IUGR, microalbumin, creatinine, cystatin $\mathrm{C}$ )

\section{Introduction}

Barker Hypothesis 1995 emphasizes the close relationship of intrauterine growth restriction (IUGR) to hypertension, coronary heart disease, diabetes mellitus and peripheral vascular disease in adulthood $^{1}$. The World Health Organization (WHO) defines small for gestational age (SGA) as a neonatal weight of less than $2500 \mathrm{~g}$ at term ${ }^{2}$. The terms IUGR and SGA are commonly used interchangeably. A more widely used definition of IUGR in the developed countries is an estimated weight less than the 10th percentile for gestational age or a weight that is less than two standard deviations below the anticipated value for the gestational age ${ }^{3}$. IUGR is reported to affect 10 $15 \%$ of pregnant women ${ }^{4}$.

\section{Objectives}

To assess renal function in infants with a history of IUGR up to 36 weeks gestation compared to infants with normal growth.

\section{Method}

The study was conducted at the H. Adam Malik Hospital Medan, Dr. Pirngadi Hospital Medan and practices of obstetricians and gynecologists. Ethical clearance was obtained from the Health Research Ethical Committee, Medical Faculty of Universitas Sumatera Utara/ H. Adam Malik General Hospital. Informed consent for the study was obtained from the pregnant mothers. The cases were pregnant mothers whose fetuses had IUGR at 28-36 weeks gestation, while controls were pregnant mothers whose fetuses had normal weights and who were matched for gestational ages as the cases. The cases were followed up and ultrasound examination was conducted every 2 weeks until 36 weeks gestation or until there was an improvement in the weight to normal values, in which instance these cases were excluded. Weighing infants was done after birth along with measurement of body length and recording Apgar scores. On day 7, examination of urine albumin, creatinine and cystatin $\mathrm{C}$ blood test were done.

In this study, the number of cases and controls were 20 each. The sample size was chosen for 
convenience. The first 20 eligible consenting mothers who attended the antenatal clinic from the time the study was commenced were chosen as the cases. The data obtained was analysed descriptively (number, size and description) along with use of student $t$ test analysis and if it did not have normal distribution Mann-Whitney test was then conducted with SPSS version 19 with the significance level at $5 \%$.

Results

Table 1 shows the characteristics of the research subjects.

Table 1: Characteristics of research subjects

\begin{tabular}{|c|c|c|c|c|c|}
\hline \multirow{2}{*}{ Characteristic } & \multicolumn{2}{|c|}{ IUGR (n=20) } & \multicolumn{2}{c|}{ Normal $(\boldsymbol{n}=\mathbf{2 0})$} & \multirow{2}{*}{ p value } \\
\cline { 2 - 5 } & mean & SD & mean & SD & \\
\hline Birth weight $(\mathrm{g})$ & $2,952.5$ & 330.79 & $3,306.75$ & 194.18 & $0.001(\mathrm{p}<0.01)$ \\
\hline Body length $(\mathrm{cm})$ & 49 & 0.81 & 50 & 0.88 & $0.012(\mathrm{p}<0.05)$ \\
\hline & Number & $\mathbf{\%}$ & Number & $\mathbf{\%}$ & \\
\hline Apgar at 1 minute & & & & & \\
5 or less & 03 & 15 & 01 & 05 & $0.605(\mathrm{p}>0.05)$ \\
More than 5 & 17 & 85 & 19 & 95 & \\
\hline Apgar at 5 minute & & & & $0 \%$ & \\
5 or less & 0 & 0 & 0 & $100 \%$ & \\
More than 5 & 20 & 100 & 20 & 50 & $1.00(\mathrm{p}>0.05)$ \\
\hline Gender & 10 & 50 & 10 & 50 & \\
Male & 10 & 50 & 10 & & \\
female & & & & & \\
\hline
\end{tabular}

Though there were 3 cases who had an Apgar score at one minute of 5 or less among the 20 infants with IUGR compared with 1 among the 20 normal weight infants, this was not statistically significant. There were no cases where the Apgar score at 5 minutes was 5 or less in either the IUGR or normal weight infants. In both IUGR and normal weight infants, the male: female distribution was $1: 1$. On day 7 after birth, levels of urine microalbumin of both infant groups were measured. Table 2 shows the different mean albumin levels between normal and IUGR infants. The differences were statistically significant. Table 3 shows the different mean creatinine levels between normal and IUGR infants. The differences were statistically significant. On examination of the albumin/creatinine ratio, by using instantaneous urine sample, it was found that the mean albumin/creatinine ratio for IUGR infants differed significantly from that of normal infants. This is shown in Table 4. Table 5 shows the mean levels of Cystatin $\mathrm{C}$ between IUGR and normal weight infants. This was not statistically significant.

Table 2: Different mean urine microalbumin levels between normal weight and IUGR Infants

\begin{tabular}{|c|c|c|c|c|c|}
\hline & Group & Number & Mean & Standard deviation & * p value \\
\hline $\begin{array}{c}\text { Microalbumin } \\
(\mathrm{mg} / \mathrm{ml})\end{array}$ & IUGR & 20 & 15.83 & 31.32 & \multirow{2}{*}{$0.001(\mathrm{p}<0.01)$} \\
\cline { 2 - 5 } & Normal & 20 & 1.9 & 0.97 & \\
\hline
\end{tabular}

*Mann-Whitney

Table 3: Different mean urine creatinine levels between normal weight and IUGR Infants

\begin{tabular}{|c|c|c|c|c|c|}
\hline & Group & Number & Mean & Standard deviation $)$ & $*$ p value \\
\hline $\begin{array}{c}\text { Creatinine } \\
(\mathrm{mg} / \mathrm{L})\end{array}$ & IUGR & 20 & 17.1 & 9.8 & $0.001(\mathrm{p}<0.01)$ \\
\cline { 2 - 5 } & Normal & 20 & 8.2 & 2.9 & \\
\hline
\end{tabular}

*Mann-Whitney

Table 4: Different mean urine albumin/creatinine ratio between normal weight and IUGR Infants

\begin{tabular}{|c|c|c|c|c|c|}
\hline & Group & Number & Mean & Standard deviation & $*$ p value \\
\hline $\begin{array}{c}\text { Albumin/ } \\
\text { creatinine ratio } \\
(\mu \mathrm{g} / \mathrm{mg})\end{array}$ & IUGR & 20 & 198 & 627.63 & $0.001(\mathrm{p}$ \\
\cline { 2 - 6 } & Normal & 20 & 24.75 & 14.07 & $<0.01)$ \\
\hline
\end{tabular}

*Mann-Whitney 
Table 5: Mean level of Cystatin C between IUGR and normal weight infants

\begin{tabular}{|c|c|c|c|c|c|}
\hline & Group & Number & Mean & Standard deviation & * p value \\
\hline \multirow{2}{*}{ Cystatin C $(\mathrm{mg} / \mathrm{ml})$} & IUGR & 20 & 1.47 & 0.27 & 0.800 \\
\cline { 2 - 5 } & Normal & 20 & 1.45 & 0.20 & $(\mathrm{p}>0.05)$ \\
\hline
\end{tabular}

$*$ t-test

\section{Discussion}

In a study in Sudan in the third trimester of normal pregnancy, the fetal kidney volumes of premature, mature and full-term infants were $5.6 \mathrm{cu} \mathrm{mm}, 9.8$ $\mathrm{cu} \mathrm{mm}$ and $10.5 \mathrm{cu} \mathrm{mm}$ respectively ${ }^{5}$. The occurrence of proteinuria in IUGR infants is caused by reduced number of nephrons, and will increase the risk of hypertension and kidney disease. With the reduction in the number of nephrons, to maintain satisfactory function, rest of the nephrons undergo hyperfiltration and hypertrophy. Hyperfiltration in the nephrons leads to an increase in intra glomerular capillary hydrostatic pressure, which in turn causes damage to the capillary walls. The damage causes a decrease in proteinuria and glomerular filtration ${ }^{6}$.

Glomerular filtration rate (GFR) is an important parameter in assessing kidney function. There are several tests for measuring GFR but the substance frequently used to assess renal impairment is creatinine. The increase in creatinine level will occur when there is a decline of GFR more than $50 \%$. Cystatin $\mathrm{C}$ measurement is more promising, especially in mild impairment of renal function compared to the use of creatinine ${ }^{7}$. Cystatin $\mathrm{C}$ does not pass the placental barrier and there is no correlation between maternal and neonatal levels, unlike creatinine, so levels of cystatin $\mathrm{C}$ in the neonate only depicts GFR of neonates, themselves ${ }^{7}$.

Since our study is a comparison of renal function of IUGR infants and normal weight infants it is to be expected that the mean weights and body lengths of the IUGR infants will be significantly less when compared to the normal weight group. There were no significant differences in the Apgar scores at 1 and 5 minutes and no significant gender differences between the IUGR group and the normal weight group. Mean urine microalbumin levels in the 20 IUGR infants were significantly higher than the levels in the 20 normal weight infants $(p<0.01)$. Mean urine creatinine levels in the IUGR infants were significantly higher than the levels in the normal weight infants $(p<0.01)$. Mean urine albumin/creatinine ratios in the IUGR infants were similarly higher than the levels in the normal weight infants $(\mathrm{p}<0.01)$. However the mean blood Cystatin C levels were not significantly different in the IUGR group and the normal weight group.

\section{Conclusions}

Mean urine albumin level, mean urine creatinine level and mean albumin/creatinine ratio of IUGR infants were significantly higher than those of normal weight infants. There was no significant difference between the mean cystatin $\mathrm{C}$ levels of IUGR infants and normal weight infants.

\section{References}

1. Fowden AL, Giussani D. Intrauterine programming of physiological systems: Causes and consequences. Physiology 2006; 21: 29-37.

https://doi.org/10.1152/physiol.00050.200 5

PMid: 16443820

2. World Health Organization. International Statistical Classification of Diseases and Related Health Problems. Geneva, Switzerland: WHO; 1992.

3. Doubilet PM, Benson CB. Ultrasound evaluation of fetal growth. In: Callen PW, editor. Ultrasonography in Obstetrics and Gynecology. Philadelphia, USA: WB Saunders; 2000.

4. American College of Obstetricians and Gynecologists. Intrauterine growth restriction. Practice Bulletin no. 12, 2000, Washington DC.

5. Adam, M, Tamboul, J, Y, Yousef, M, Sulieman, A, The normal fetal kidney in normal pregnant ladies, Journal of American Science 2013; 9(12): 794-7.

6. Brenner BM, Lawler EV, Mackenzie HS. The hyperfiltration theory: A paradigm shift in nephrology. Kidney International 1996; 49: 1774-7.

https://doi.org/10.1038/ki.1996.265

PMid: 8743495

7. Westhuyzen J. Review: Cystatin C: a promising marker and predictor of impaired renal function. Annals of Clinical and Laboratory Science 2006; 6(4). 38794 